\title{
ON THE EVOLUTIONARY STABILITY OF THE FEMALE- BIASED SEX RATIO IN THE WOOD LEMMING (MYOPUS SCHISTICOLOR): THE EFFECT OF INBREEDING
}

\author{
J. MAYNARD SMITH \\ School of Biological Sciences, University of Sussex, Falmer, Brighton, Sussex BN1 9QG, \\ England \\ and \\ N. CHR. STENSETH \\ Zoological Institute, University of Oslo, P.O. Box 1050, Blindern, Oslo 3, Norway
}

Received 27.iv.78

\section{SUMMARY}

The evolutionary stability of the female-biased sex ratio observed in the wood lemming (Myopus schisticolor) is discussed. The hypothesis analysed is that the skewed sex ratio is maintained as a result of partial and/or recurrent inbreeding. Fredga et al. (1976, 1977) have suggested that an X-linked mutant gene, $\mathrm{X}^{*}$, affects the male-determining action of the $\mathrm{Y}$ chromosome, thus converting some $\mathrm{XY}$ individuals into females. By a mechanism of selective non-disjunction in the foetal ovary only $\mathrm{X}^{*}$-carrying eggs are produced. In particular the stability of that genetic mechanism (or the $\mathrm{X}^{*}$ chromosome) is analysed by considering the introduction of a "suppressing " sex-linked mutant gene $Y^{*}$. Several deterministic simulation models assuming father-daughter and/or brother-sister matings have been developed and analysed. It is concluded that in the case of extremely strong inbreeding, the hypothesised genetic mechanism may, as a result, be evolutionarily stable. Interpreting field observations on microtine rodents in general it is concluded that only a few species are likely to experience such extreme cases of inbreeding. The wood lemming and the related collared lemming (Dicrostonyx troquatus), another case which seems to have $\mathrm{XY}$-fenales, are likely to exhibit sufficiently strong inbreeding.

\section{INTRODUCTION}

WILD populations of the wood lemming (Myopus schisticolor) are characterised by exaggerated density cycles and an excess of females (70-80 per cent females; Kalela and Oksala, 1966). Breeding experiments show that this excess of females is due to a significant proportion of females producing only daughters. Recently Fredga et al. (1976) have, for several different populations, demonstrated that two sex chromosome types of females exist in the wood lemming; XX and XY. Wachtel et al. (1976) showed that XY females are $\mathrm{H}-\mathrm{Y}$ antigen negative whereas males (XY) are, as usual, $\mathrm{H}-\mathrm{Y}$ antigen positive. Thus, the genes on the $\mathrm{Y}$ chromosome coding for maleness seem to be lacking or inactive in XY females.

Fredga et al. $(1976,1977)$ have hypothesised a gene on an $\mathrm{X}$ chromosome $\left(\mathrm{X}^{*}\right)$ which depresses the male determining genes on a Y chromosome and causes a selective non-disjunction in the foetal ovary (a meiotic drive) so that only $\mathrm{X}^{*}$-carrying eggs are produced. The $\mathrm{X}^{*}$-gene is supposed to have no effect on $\mathrm{X} * \mathrm{X}$ females. No difference in litter size or in any other phenotypic character has been observed among the different female types; 
in particular there are no detectable differences in their fertility. Although Fredga and his co-workers have not shown any evidence, other than circumstantial, for the existence of a mutant $\mathrm{X}^{*}$-gene, their hypothesis is consistent with available data. The purpose of this paper is to evaluate the evolutionary stability of this hypothetical genetic mechanism.

We distinguish between "ecological" and "evolutionary" stability. By ecological stability we mean that a given genetic system is stable provided that no genetic modifiers are introduced; by evolutionary stability we mean that the genetic system is also capable of resisting the introduction of some defined types of genetic modifier. In this sense, Fisher's (1930) assertion that the $1: 1$ sex ratio is stable was an assertion of evolutionary stability against autosomal or X-linked modifiers expressed in a parent and modifying the sex ratio among its offspring.

Bengtsson (1977) has shown that the system hypothesised by Fredga $e$ al . (1976) for the wood lemming is, in a panmictic population, stable in ecological time, given that all females in the population mate. As shown below the system has also a stable ecological equilibrium under various regimes of inbreeding, again given that all females mate.

Stenseth (1978) has suggested that the sex ratio distortion in the wood lemming may be evolutionarily stable due to recurrent inbreeding during population cycles. Particularly, brother-sister and/or father-daughter matings may be common. Due to the extremely low densities during a cyclic low and early increase phase, this inbreeding effect may be larger for wood lemmings than for most other microtines.

The explicit purpose of this paper then is to evaluate Stenseth's (1978) suggestion. This will be done by considering, under different mating regimes, the extent of inbreeding needed to prevent modifiers suppressing the $\mathrm{X}^{*}$-gene from being selected. The approach taken is to analyse deterministic simulation models.

\section{Brother-Sister MATINGS}

\section{(i) Ecological stability}

In the system hypothesised by Fredga et al. $(1976,1977)$ three types of matings are possible:

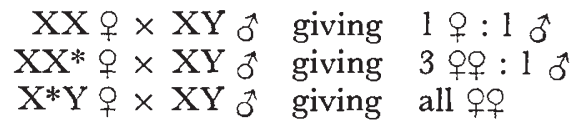

The following discrete generation model was analysed. Any male may mate several times in each generation. In those families which do contain males, we assume that in every generation a fraction $k$ of all females mate with a brother, and $1-k$ randomly. For families containing no males, two extreme assumptions were simulated:

(i) Females with no brother all mate randomly.

In this case the system has a globally stable state in ecological time with both $\mathrm{X}$ and $\mathrm{X}^{*}$ chromosomes present for any value of $k$; at equilibrium, there will be one-third of each female type. 
This coincides with Bengtsson's (1977) result: In effect we have assumed 100 per cent effective meiotic drive; i.e. $\mathrm{X} * \mathrm{Y}$ females produce only $\mathrm{X}^{*}$ carrying eggs, making Bengtsson's $n$ equal to 1 . Furthermore, $\mathrm{X}^{*} \mathrm{Y}$ females are assumed to have the same fertility as $\mathrm{XX}$ and $\mathrm{XX}^{*}$ females, thus Bengtsson's $f$ is equal to $l$ and independent of the degree of inbreeding. The one-third frequency of the three female types may then be deduced from Bengtsson's Eq. (2). Consequently, under this mating scheme Bengtsson's model and results are "insensitive" to inbreeding.

(ii) A fraction $1-k$ of females from litters with no males mate randomly, and the remainder are in effect sterile.

In this case, the $\mathrm{X}, \mathrm{X}^{*}, \mathrm{Y}$ system exhibits a globally stable equilibrium with both $\mathrm{X}$ and $\mathrm{X}^{*}$ chromosomes present when $k$ is less than one-half. For larger values of $k$, the $\mathrm{X}^{*}$ disappears.

Again these results may be deduced from Bengtsson's (1977) model: Now, Bengtsson's fertility parameter for the $\mathrm{X}^{* \mathrm{Y}}$ females, $f$, is equal to $1-k$. Bengtsson demonstrated that $\mathrm{X}^{*}$ will be lost from the population if $2(1-k) \leqq 1$, i.e. if $k \geqq \frac{1}{2}$. Otherwise the $\mathrm{X}^{*}, \mathrm{X}, \mathrm{Y}$ system is globally stable with equilibria as given by Bengtsson's Eq. (2).

An interesting point emerges: Bengtsson assumed that all females mate and that the reduced fertility of $\mathrm{X}^{*} \mathrm{Y}$ females is due to the production of dead YY offspring. We have demonstrated an alternative interpretation of his model. However, in this latter case the model and the results are not "insensitive" to inbreeding. This is due to a fraction $k$ of the $\mathrm{X} * \mathrm{Y}$ females having in effect zero fitness, because not all females are able to find a mate.

\section{(ii) Evolutionary stability}

To be stable in an evolutionary sense, the system must resist the introduction of mutants tending to normalise the sex ratio. Following Fisher (1930), such mutants are expected to be selected in panmictic populations. However, following Hamilton (1967) and Maynard Smith and Stenseth (unpublished) a female-biased optimal sex ratio is expected under inbreeding. Two kinds of mutants could normalise the sex ratio:

(a) an autosomal "supressor" mutant, in the presence of which $X^{*} \mathrm{Y}$ individuals develop as normal males; and

(b) a "suppressor" $\mathrm{Y}^{*}$ chromosome, so that $\mathrm{X}^{*} \mathrm{Y}^{*}$ individuals are normal males.

Of these two mutant types we have simulated only the latter, since it is both more plausible (e.g. Wood and Newton, 1976) and easier to analyse. Our question is then: given a population with the $\mathrm{X}^{*}, \mathrm{X}$ and $\mathrm{Y}$ chromosomes would a mutant $\mathrm{Y}^{*}$ chromosome be established, and if so, would it go to fixation?

In a random mating population where all females are mated, $\mathrm{Y}^{*}$ will always be favoured over the $\mathrm{Y}$ chromosome since the latter has the meiotic drive against it (F. Christiansen and B.-O. Bengtsson, personal communication). Under inbreeding this advantage of $\mathrm{Y}^{*}$ over $\mathrm{Y}$ should be contrasted with the favourable effect of an operative $\mathrm{X}^{*}$ chromosome producing a surplus of females. Consequently, the fate of a $\mathrm{Y}^{*}$ chromosome introduced in an $\mathrm{X}^{*}, \mathrm{X}, \mathrm{Y}$ population is not obvious under inbreeding. 
The following results emerge from the simulations:

In the model (i) (i.e. females with no brothers all mate randomly), the population evolves until it contains only $\mathrm{X}^{*}$ and $\mathrm{Y}^{*}$ chromosomes and a $1: 1$ sex ratio is restored. This is clearly due to the fact that the advantage of producing excess females disappears for the $\mathrm{X}^{*} \mathrm{Y}$ females (which in this case always outcross). Thus even if $k$ is large, extensive outcrossing will continue; 33 per cent of the females will always mate randomly.

In model (ii) (i.e. a fraction $k$ of females with no brother are effectively sterile), a $1: 1$ sex ratio is also restored for all values of $k$. The final chromosome combination depends on the value of $k$. For $k<0.7$ (approx.), the final population contains only $\mathrm{X}^{*}$ and $\mathrm{Y}^{*}$ chromosomes; for $k>0 \cdot 7$, the final population contains mainly $\mathrm{X}$ and $\mathrm{Y}$ chromosomes, with low frequency of $\mathrm{Y}^{*}$. (Note that in the absence of $\mathrm{X}^{*}$, chromosomes $\mathrm{Y}$ and $\mathrm{Y}^{*}$ are indistinguishable.)

Thus in both cases, with the introduction of $\mathrm{Y}^{*}$, the population finishes up with a typical system of male heterogamety and a 1 : l sex ratio. Hence, it is unlikely that the sex ratio determining mechanism of the wood lemming could be maintained by brother-sister matings only.

As is apparent we have assumed that both effects of the $\mathrm{X}^{*}$-gene are suppressed; i.e. both the meiotic drive and the sex determining mechanism of the $\mathrm{X}^{*}$ gene.

A mutant suppressing only the meiotic drive would seem to have no advantage as $\mathrm{X}^{*} \mathrm{Y}$-females then would produce some $\mathrm{Y}$-eggs, a fraction of which would develop into (dead) $\mathrm{YY}$ zygotes; thus, $\mathrm{X} * \mathrm{Y}$ females would have reduced fertility. In fact, this is an argument for expecting an approximately 100 per cent effective meiotic drive. Such a high efficiency is consistent with field and laboratory observations interpreted on the basis of Bengtsson's (1977) model.

A mutant depressing only the sex determining effect of the $\mathrm{X}^{*}$-gene may be plausible. However, in this case the meiotic drive would operate in $\mathrm{X} * \mathrm{Y}$ males, and the problem essentially reduces to the one discussed by Maynard-Smith and Stenseth (unpublished). They showed that a femalebiased sex ratio is expected to be optimal under inbreeding.

\section{Father-daughter matings}

\section{(i) Ecological stability}

Two extreme models have been simulated:

(i) Any male lives for only two generations, so that he may mate with his daughters but not grand-daughters (including those daughters produced when mating his first daughters). Males may mate several times per generation.

Suppose that, as a long-term average, a fraction $1-R$ of all females mate with their fathers, and $R$ mate randomly. All female offspring of fatherdaughter matings mate randomly, since they have no surviving father. If a fraction $k$ of female offspring from random matings mate with their fathers, then

or

$$
k R=1-R,
$$

$$
R=1 /(1+k) \text {. }
$$


Thus, a maximum of 50 per cent of all female matings will be with the father. In this case the model may also be interpreted as an alternating inbreeding-outcrossing situation.

(ii) In the other extreme case we assume the father to be immortal: A fraction $k$ of all females mate with their father and $1-k$ randomly. For $k \simeq 1$, this system is obviously meaningless, since it implies an immortal male. However, in the cases where $k$ is not very close to 1 , this model imitates the case of most females being able to find a father even if he should be mortal.

Repeated breeders, with a social organisation excluding immature males (e.g. sons), while females are allowed to mature at their place of birth, represent such situations. Microtines illustrate such a biological situation (Stenseth et al., 1977).

In both cases the $\mathrm{X}^{*}, \mathrm{X}, \mathrm{Y}$ system is ecologically stable with an equilibrium of one-third of each of the three different female genotypes. As all females are mated Bengtsson's (1977) model with $f=1$ applies: thus the stability of the $\mathrm{X}^{*}, \mathrm{X}, \mathrm{Y}$ system is "insensitive " to inbreeding.

\section{(ii) Evolutionary stability}

However, should a mutant $\mathrm{Y}^{*}$ arise, will it be established in the population?

In model (i) (i.e. fathers only being able to mate with their daughters but not with their grand-daughters), Y* will always go to fixation, and a 1:1 sex ratio with a typical male heterogametic system be restored. Presumably a maximum inbreeding frequency of one-half is too low judged by the results from the next model.

In model (ii) (i.e. immortal males), $\mathrm{Y}^{*}$ will be established for $k<0 \cdot 75$ (approx.). However, for larger values of $k$ the $\mathrm{X}^{*}, \mathrm{X}, \mathrm{Y}$ system is evolutionarily stable as a result of inbreeding.

\section{Combined FAther-DAUghter AND BRother-sister MATINGS}

We have simulated the case where any female may engage in three types of matings: she may mate with her father, her brother, or outcross. Again two models have been analysed:

(i) Any male lives for only two generations. In any generation he may mate several times. A fraction $1-R$ of all matings of a female is, in a stable situation, assumed to be with her father. A fraction $k$ of all females from random matings, mate with their father. Again, $R=1 /(1+k)$. Furthermore, a fraction $k$ of all females from the father-daughter matings mate with their brother, if any; otherwise they outcross.

For the same reason as given for the other equivalent models, the $X^{*}$, $\mathrm{X}, \mathrm{Y}$ system is always globally stable.

In this case, whatever the value of $k$, the population evolves until it only contains $\mathrm{X}^{*}$ and $\mathrm{Y}^{*}$ chromosomes. However, for larger values of $k$, the frequency of $Y^{*}$ chromosomes (which is assumed to be low to begin with) increases very slowly. 
(ii) In the other extreme case, the fathers are assumed to be immortal. A fraction $k$ of all females mate with their father and a fraction $n$ mate with a brother if any. We now assume that this fraction $n$ of females are effectively sterile if they do not have a brother. This latter assumption will make the effect of inbreeding on the evolutionarily stable sex ratio less than it actually is. This may outweigh some of the bias due to the existence of immortal males. A fraction $1-k-n$ of all females outcross.

The $\mathrm{X}^{*}, \mathrm{X}, \mathrm{Y}$ system may be analysed analytically by applying Bengtsson's model: a fraction $k$ of $\mathrm{X}^{*} \mathrm{Y}$ females have $f=1, n$ have $f=0$ and $1-k-n$ have $f=1$, i.e. the average $f=1-n$. Bengtsson deduced that the system will be globally stable with both $\mathrm{X}$-chromosomes present if and only if $2(1-n)>1$ or $n<0 \cdot 5$. (Notice that $\max (n)=1-k$.)

The following results illustrate the behaviour of the latter model when a $\mathrm{Y}^{*}$ chromosome is introduced:

For $k=0.4$ and $n=0.3$ the population evolves until $\mathrm{Y}^{*}$ has gone to fixation and a $1: 1$ sex ratio is restored. For $k=0.4$ and $n=0.5$ the population evolves until only $\mathrm{XX}$ and $\mathrm{XY}$ individuals remain. For $k=0.5$ and $n=0.2$ the population evolves until only $\mathrm{X}^{*} \mathrm{X} *$ and $\mathrm{X} * \mathrm{Y} *$ remain. This agrees with the above analytical results for the $\mathrm{X}^{*}, \mathrm{X}, \mathrm{Y}$ system.

For $k=0.5$ and $n=0.3$ the $\mathrm{Y}^{*}$ chromosome will not be established in the population. A stable frequency of $\mathrm{XX}, \mathrm{XX}^{*}$ and $\mathrm{X} * \mathrm{Y}$-females equal to $0 \cdot 555,0 \cdot 222$, and 0.222 evolves. These frequencies may be found from Bengtsson's (1977) Eq. (2) with $f=1-n$ (assuming a 100 per cent effective meiotic drive). For larger $n[\max (n)=0.5$ in this case] increasingly more females will be of the XX-genotype. Again this is due to many $\mathrm{X}^{*} \mathrm{Y}$ females being effectively sterile.

\section{Conclusion}

We have shown that the $\mathrm{X}^{*}, \mathrm{X}, \mathrm{Y}$ system is never stable against introduction of $\mathrm{Y}^{*}$ for (i) brother-sister matings only, (ii) father-daughter matings if the father stays alive for two generations only, and (iii) fatherdaughter and brother-sister matings, where any male stays alive for two generations only and where any female may be mated in every generation. The $\mathrm{X}^{*}, \mathrm{X}, \mathrm{Y}$ system is stable (iv) for the artificial case in which all matings are father-daughter, which implies potentially immortal males. (v) If both father-daughter and brother-sister matings occur, the system is stable with 0.5 of females mating their fathers, 0.25 their brothers, and 0.25 mating randomly.

Thus we have demonstrated that, in theory, the peculiar sex ratio and sex determining system in the wood lemming may be maintained through evolutionary time by extensive inbreeding. We give reasons below for thinking that the required extreme degree of inbreeding may in fact occur. The alternative would be to suppose that the $\mathrm{X}-\mathrm{X}^{*}-\mathrm{Y}$ system is of relatively recent origin and is not stable against genetic modification. We cannot rule out the possibility, but it seems unlikely in view of the extensive occurrence of "resistant" X chromosomes in Aedes aegypti in the presence of driving $\mathrm{Y}$ chromosomes (Wood and Newton, 1976). In fact there is some evidence that the sex ratio distortion observed in wood lemmings is an ancient one (cf. Fredga et al., 1976). 
The models we have analysed to arrive at this conclusion are, however, very artificial. In particular, it may be argued that to consider a model population with discrete and synchronous generations is not valid for microtines. However, many studies on microtines in northern regions [e.g. Myllymäki's (1977) on field voles, Microtus agrestis, in Central Scandinavia] show that during the main breeding season litter production is in effect synchronised. Presumably this is due to (i) the simultaneous spring initiation of reproduction, (ii) that each female (under natural conditions) produces litters at an interval of approximately 25 days (Ilmén and Lahti, 1968), and (iii) that juvenile females may mature at an age of 25 days (Ilmén and Lahti, 1968).

All models discussed assume, in effect, infinite family size; i.e. except for $\mathrm{X}^{*} \mathrm{Y}$-females, all females will always produce at least one male. This bias is likely to be only slight. In captivity most females are reported to have four young in each litter (Kalela and Oksala, 1966). For microtines generally, litter sizes estimated from laboratory samples are considerably less than those estimated from field samples (e.g. Myllymäki, 1977). Thus, Ognev (1963) reported an average of 5.2 (range 3-7) for wild individuals. Based on observations from other lemming species under field conditions (e.g. Batzli et al., 1974 on Lemmus trimucronatus in Arctic Alaska) the realised litter size may be even higher. Based on Maynard Smith and Stenseth's (unpublished) model incorporating finite family sizes, for $k=0.5$ a litter size of 10 may be sufficiently close to an infinitely large litter size to render the bias unimportant.

Unfortunately, little information on the demography of wild wood lemming populations exists. This is certainly due to the species being very difficult to capture in traps. No information on the breeding structure of any wild microtine population exists. Thus, mainly circumstantial evidence from cyclic microtines in general must be relied upon. However, several such general features seem to exist (cf. Krebs and Myers, 1974). Based on such information, Stenseth (1978) points out that inbreeding as a necessity may be extensive for all cyclic microtines, and particularly so for the wood lemming. Essentially this is due to extreme low density and very patchy distribution during the low and early increase phases.

Our reasons for presuming, on the basis of the previously discussed models, that inbreeding may be responsible for the evolutionary maintenance of the $\mathrm{X}^{*}, \mathrm{X}, \mathrm{Y}$ chromosome system are:

(1) The degree of inbreeding necessary for maintaining the $\mathrm{X}^{*}, \mathrm{X}, \mathrm{Y}$ system may not be as large as suggested by the models discussed in the previous sections. This is due to our having disregarded other types of inbreeding than father-daughter and/or brother-sister matings. Other forms of mating between close relatives may be expected to be common during cyclic low and early increase phase.

(2) We have pointed out the low fitness of $X^{*} Y$ females due to their producing daughters only, and that this was the main reason for the $Y^{*}$-mutant being selected. In the wild this effect is not likely to be of great significance. The following genotypes are produced by the three different females types:

$\mathrm{XX}$ females produce $\mathrm{XX}$ and $\mathrm{XY}$ genotypes in a $1: 1$ ratio; $\mathrm{X}^{*} \mathrm{X}$ females produce $X^{*} X, X^{*} Y, X X$ and $X Y$ genotypes in a $1: 1: 1: 1$ 4 ] $/ 2-\mathrm{F}$ 
ratio; and $X^{*} Y$ females produce $X^{*} X$ and $X Y$ genotypes in a $1: 1$ ratio.

Thus in a group of partially inbreeding individuals, males are expected to be born at the latest in the second generation starting with any pair.

(3) Fathers (i.e. mature males) may tend to be in the vicinity of their daughters for several generations (Myllymäki, 1977; Stenseth, 1978). Myllymäki (1977) shows for the field vole (Microtus agrestis) that overwintered males become mature in spring and reproduce several times (5-8) before dying in the fall. The breeding biology and structure of the population is such that in the field, females born during the summer tend to mature much faster than males. A female may mature at an age of 20 days and 20 days later they may have their first litter. For the wood lemming these figures are 25 days (cf. Ilmén and Lahti, 1968). If and when their brothers mature they are likely to be driven away by the mature males (including their father; c.f. information compiled and interpreted by Stenseth et al., 1977). Thus, a high degree of father-daughter mating is likely to result.

(4) The great majority of individuals are likely to overwinter only once (Myllymäki, 1977). Thus the individuals present in a "survival pocket" (cf. Lidicker, 1973) at the initiation of a new breeding season are likely to be siblings or other close relatives.

(5) Wood lemmings are characterised by more exaggerated density fluctuations than most other microtines (Kalela and Oksala, 1966). The low phases are particularly characterised by extremely low densities necessitating high degrees of inbreeding.

According to Fredga et al. (1976) a similar X*, X, Y system seems to be found in the collared lemming (Dicrostonyx torquatus $[=$ groenlandicus?]) in the arctic tundra of U.S.S.R. (Gileva and Lobanova, 1974). Interestingly, a similar female-biased sex ratio was observed. Interpreting in the same way the observations of Rausch and Rausch (1972) on the collared lemming (D. torquatus [= groenlandicus]) from Unnak. Island in Alaska these observations may be intepreted as similar to the wood lemming (Fredga et al., 1976). Rausch and Rausch (1972, p. 376) state explicitly that some females gave birth to "a lower than normal proportion of male off-spring ".

Like the wood lemming, the collared lemming, at least on the northernmost part of the Arctic tundra, is characterised by extremely low densities and patchy distribution for extensive periods (cf. Ognev, 1963; Batzli, 1975). Thus, the collared lemmings may be another group of species for which the $\mathrm{X}^{*}, \mathrm{X}, \mathrm{Y}$ system is stable. Whether the wood lemming and collared lemming both have the same $\mathrm{X}^{*}, \mathrm{X}, \mathrm{Y}$ system because they are related and have inherited it from a common ancestor [thus indicating the evolutionary stability of the system as assumed by Bengtsson (1977)]; or whether they both have the same chromosome system because they have similar population dynamics, is difficult to distinguish at present. Palentological investigations of Kowalski (1977) indicate, however, that the genera Myopus and Dicrostonyx are not closely related. The modern genus Dicrostonyx forms 
a distinct group, whereas Synaptomys-Lemmus-Myopus form another distinct group. This suggests that the similar chromosome systems in Myopus and Dicrostonyx may be a recent phenomenon evolved as a response to similar population dynamics. Further, the two alternatives may be distinguished if local populations differ with respect to the presence of the $\mathrm{X}^{*}, \mathrm{X}$, and $\mathrm{Y}$ system.

According to R. L. Rausch (cited from Whitney (1973)) similar chromosomal systems have been observed in the root vole (Microtus oeconomus) populations in the taiga of interior Alaska. Contrary to the wood lemming and collared lemming this observation represents, as far as we can see, a local phenomenon. To our knowledge, there are no other observations on root voles indicating that some females give birth only to females. Furthermore, Fredga and Stenseth (unpublished data) have shown that a root vole population in Norway has a normal chromosome system. These observations may be interpreted as follows: The result of Bengtsson (1977) and the simulation models discussed in the present paper, suggest that the $\mathrm{X}^{*}, \mathrm{X}$, $Y$ system is ecologically stable in a global sense. Thus, should a mutant $X^{*}$ chromosome occur, it will always be established in the population. However, our analysis also shows that extensive inbreeding is needed for such a system, should it be established in the first place, to be stable against the introduction of mutants "suppressing" the $\mathrm{X}^{*}$-mutant. Root voles in general and the population studies by Whitney (1973) in particular are unlikely to experience sufficiently low densities to necessitate the extensive degree of inbreeding necessary for maintenance of the $X^{*}, X, Y$ system. We therefore suggest that the chromosome configuration of the root vole may be evolutionarily unstable.

Acknowledgments.--This work was supported by a grant from the British Council. We thank $\mathrm{K}$. Fredga for stimulating discussions concerning the interpretation of observations on chromosome " abnormalities", and K. Kowalski on the systemic position of the modern lemming genera. Both K. Fredga and B. O. Bengtsson are thanked for providing excellent comments on an earlier version of the manuscript.

\section{REFERENCES}

BATZLI, G. o, 1975. The role of the small mammals in arctic ecosystems. In Small Mammals: Their Productivity and Population Dynamics, eds. F. B. Golby, K. Petrusewicz, and L. Ryszkowski, pp. 243-268. Camb. Univ. Press, Cambridge.

BAtzli, G. O., STENSETH, N. C., AND FITZGerald, B. M. 1974. Growth and survival of suckling brown lemmings, Lemmus trimucronatus. 7. Mammal., 55, 828-831.

Bengtss on, B.-o. 1977. Evolution of sex ratio in the wood lemming. In Measuring Selection in Natural Populations, eds. F. B. Christiansen and T. M. Fenchel, pp. 333-343. Springer Verlag.

FISHER, R. A. 1930. The Genetical Theory of Natural Selection, 272 pp. Clarendon Press.

FREDGA, K., GRopp, A., WINkING, H., AND FRANK, F. 1976. Fertile XX- and XY-type females in the wood lemming Myopus schisticolor. Nature, 261, 225-227.

FREDGA, K., GROPP, A., WINKING, H., AND FRANK, F. 1977. A hypothesis explaining the exceptional sex ratio in the wood lemming (Myopus schisticolor). Hereditas, 85, 101-104.

Grleva, E. A., AND lobanova, N. A. 1974. Complex chromosome variation in arctic lemming and taxonomy of the genus Dicrostonyx. Proc. 1st Int. Theriolog. Congr., Moscow, 1, $191-192$.

HAMIlton, w. D. 1967. Extraordinary sex ratios. Science, 156, 447-488.

ILMÉN, M., AND LAHTI, s. 1968. Reproduction, growth and behaviour in the captive wood lemming, Myopus schisticolor (Lilljeb.). Ann. Zool. Fennici, 5, 207-219. 
kalela, o., AND oksala, T. 1966. Sex ratio in the wood lemming, Myopus schisticolor (Lilljeb.), in nature and in captivity. Ann. Univ. Turkuensis, Ser. AII, 37, 1-24.

kowalski, к. 1977. Fossil lemmings (Mammalia, Rodentia) from the Pliocene and early Pleistocene of Poland. Acta. Zool. Cracov, 22, 279-317.

kREBS, G. J., AND myers, J. H. 1974. Population cycles in small mammals. Adv. Ecol. Res., 8, 269-399.

LIDICKER, W. Z., JR. 1973. Regulation of number in an island population of California vole: a problem in community dynamics. Ecol. Mongr., 43, 271-302.

MYLLYMÄKI, A. 1977. Demographic mechanisms in the fluctuating populations of the field vole Microtus agrestis. Oikos, 29, 468-493.

oGNev, s. I. 1963. Mammals of the USSR and Adjacent Countries, Vol. 6, Rodents. Israel Program for Scientific Translations.

RAUSCH, R. L., AND RAUSCH, V. R. 1972. Observations on chromosomes of Dicrostonyx torquatus stevensoni Nelson and chromosomal diversity in varying lemmings. $Z$. Säugertierkunde, 37, 372-384.

STENSETH, N. C. 1978. Is the female-biased sex ratio in wood lemming Mycopus schisticolor maintained by cyclic inbreeding? Oikos, 30 (in press).

STENSETH, N. C., HANSSON, L., MYLLYMÄKi, A., ANDERSSON, M., AND KATILA, J. 1977. General models for the population dynamics of the field vole Microtus agrestis in Central Scandinavia. Oikos, 29, 616-642.

WAGhtel, s. s., Koo, G. C., OHNo, s., GRopP, A., DEv., v. G., TANTRAVAhi, R., Miller, D. A., AND MILLER, O. J. 1976. H-4 antigen and the origin of X4 female wood lemmings (Myopus schisticolor). Nature, 264, 638-639.

WHITNEY, P. H. 1973. Population biology and energetics of three species of small mammals in the taiga of interior Alaska, 254 pp. Ph.D. thesis, Univ. of Alaska.

WOOD, R. J., AND NEWTON, M. E. 1976. Meiotic drive and sex ratio distortion in the mosquito Aedes aegypti. Proc. Int. Congr. Ent., pp. 97-105. 